\title{
FREQUENCY OF CONGENITAL ANOMALIES OF THE KIDNEY AND URINARY TRACT BY MEANS OF ULTRASONOGRAPHY IN NEONATES AT A TERTIARY-CARE HOSPITAL
}

\author{
Uzma Rasool, Saqib Ur Rehman*, Saeed Bin Ayaz*, Ghulam Rasool Tariq, Ghulam Ghaus Shah** \\ Shaheen Diagnostic, Jhelum Cantt, Pakistan, *Combined Military Hospital Jhelum/National University of Medical Sciences (NUMS) Pakistan, \\ **Rehman Medical Institute, Peshawar Pakistan
}

\begin{abstract}
Objective: To determine the frequency of congenital anomalies of the kidney and urinary tract by means of ultrasound in neonates.

Study Design: Cross-sectional study.

Place and Duration of Study: Department of Radiology and Diagnostic Imaging, Rehman Medical Institute, Peshawar, from May 2015 to Jan 2016.

Methodology: A total of 150 neonates reporting for routine abdominal ultrasonography were included. Honda Convex Scanner model HS-2000 with probe of frequency of 5-7 MHz was used for the ultrasonography.

Results: Mean age of the neonates was $13.8 \pm 7.5$ days. Seventy-six (50.7\%) were male and 74 (49.3\%) were female. Congenital anomalies of the kidney and urinary tract were observed in $10(6.7 \%)$ neonates. Most neonates had more than one anomaly. The left side was involved in $6(4 \%)$ neonates while right side was involved in $4(2.7 \%)$. Hydronephrosis was the most common abnormality found in $8(5.3 \%)$ cases. The location of kidneys was abnormal (ectopic) in 2 (1.3\%) neonates. Abnormal dimension was seen in seven cases and abnormal corticomedullary differentiation was found in 5 (3.3\%) cases. Non-symmetrical cases were 5 (3.3\%). Hydroureter was observed in $3(2 \%)$ neonates and urinary bladder was abnormal in 2 (1.3\%) neonates.

Conclusion: The frequency of congenital anomalies of the kidney and urinary tract in neonates by means of postnatal ultrasonographic scan in our study population was $6.7 \%$. Hydronephrosis was the most common anomaly.
\end{abstract}

Keywords: Hydronephrosis, Neonates, Urogenital abnormalities, Ultrasonography.

This is an Open Access article distributed under the terms of the Creative Commons Attribution License (https://creativecommons.org/licenses/by-nc/4.0/), which permits unrestricted use, distribution, and reproduction in any medium, provided the original work is properly cited.

\section{INTRODUCTION}

Congenital anomalies of the kidney and urinary tract (CAKUT) comprise of a wide range of structural malformations that result from defects in the morphogenesis of kidney and/or the urinary tract. These malformations may happen at the level of the kidney (e.g., hypoplasia and dysplasia), collecting framework (e.g., hydronephrosis and megaureter), bladder (e.g., ureterocele and vesicoureteral reflux), or urethra (e.g., reverse urethral valves) ${ }^{1}$. The prevalence of CAKUT reported in the two related studies had been $0.16 \%$ and $0.6 \%$ respectively ${ }^{2,3}$.

Different methods are used for screening of CAKUT. Ultrasonography is one such modality and is simple, easily accessible, in-expensive, and non-invasive method for screening. Antenatal ultrasonographic fetal assessment is carried out to determine the gestational age, monitor fetal growth, identify multiple pregnancies, and detect congenital anomalies, most importantly the CAKUT. The sensitivity of this second trimester anomaly scan is variable and different values of $44 \%, 27.8 \%, 43.8 \%$, and $100 \%$ have been reported ${ }^{4-7}$.

Correspondence: Dr Saqib Ur Rehman, Classified Specialist, Combined Military Hospital, Jhelum Pakistan

Received: 28 Feb 2020; revised received: 03 Jun 2020; accepted: 10 Jun 2020
This range in reported sensitivity probably has resulted from different identification and classification criteria that may produce a bias in results. Other factors affecting the outcomes are the time of pregnancy when the ultrasound is performed, the number of times ultrasound is performed during gestation, and the skill of the ultrasonographer. If antenatal ultrasound turns out to be normal, the child has no scan after birth for many years until the urinary symptoms and complications become noticeable. Occasionally, abnormalities discovered during a prenatal ultrasound test turn out to be normal after a postnatal ultrasound check. Choi et al ${ }^{8}$, observed that $23.4 \%$ of postnatal examinations, which were diagnosed antenatally as CAKUT, turned out to be normal. Similar observations were noted by Dulgher off and colleagues as many CAKUT diagnosed during second trimester emerged as false positives during postnatal ultrasound examination ${ }^{5}$. On the other hand, Stolz et al ${ }^{9}$, reported benefit of postnatal ultrasound examination, as it detected undiscovered abnormalities in the prenatal ultrasound examinations. Thus, all patients diagnosed for various renal abnormalities during pregnancy must undergo a postnatal scan to verify the findings and initiate appropriate therapy ${ }^{8}$.

So far, little has been available in the data regarding postnatal scans for CAKUT in Pakistan. With this 
study, we intended to add information regarding the frequency and type of CAKUT in Pakistani neonates by means of postnatal scan. This would help in promoting ultrasound screening in early infancy in Pakistan and may facilitate early treatment that can prevent renal dysfunction in later life.

\section{METHODOLOGY}

It was a cross-sectional study carried out in the department of Radiology and Diagnostic Imaging, Rehman Medical Institute Peshawar Pakistan, from May 2015 to January 2016. A sample size of 106 neonates was calculated according to the World Health Organization sample size calculator for single proportion while taking confidence level of $99 \%$, anticipated population proportion of $0.16 \%$, and absolute precision of 0.01 .

After approval from the Ethics Review Committee of Rehman Medical Institute Peshawar, through convenient sampling, we included all male and female neonates, presenting within 28 days after birth to the department, for generalized sonographic scan of the abdomen. The research did not include seriously ill newborns who were hospitalized to the critical care unit. Informed and written consent was taken from the parents/guardians of the babies. During the study, name, gender, age, hospital registration number, and urological pathologies found on ultrasonographic examinations were noted. All information was recorded on especially designed proformas. Honda Convex Scanner model HS-2000 (Honda Electronics Co. Ltd., Oiwacho, Toyohashi Aichi, Japan) with probe frequency of 5-7 MHz was used for the ultrasonographic evaluation. Recordings consisted of six bilateral renal images, including one longitudinal and two transverse images obtained in the supine position. The anterior-posterior renal pelvic diameter was measured on transverse images of the kidneys to look for magnitude of hydronephrosis. The urinary bladder was also observed in the supine position. Images were recorded when abnormalities were identified.

Ultrasonography was carried out by a resident radiologist under the supervision of an experienced consultant radiologist. The following characteristics of the kidneys were assessed: unilateral absence, abnormal location, dimensional abnormality (length $\leq 35 \mathrm{~mm}$ or $\geq 60 \mathrm{~mm}$ ), asymmetry of left and right (difference of $10 \mathrm{~mm}$ or more), corticomedullary differentiation, and presence of hydronephrosis. Hydronephrosis was graded according to the Society of Fetal Ultrasound Criteria as Grade-1 (anteroposterior renal pelvis diameter
$<10 \mathrm{~mm}$ without dilation of the calyces nor parenchymal atrophy), Grade-2 (renal pelvis diameter 10-15 mm including a few calyces), Grade-3 (Renal pelvis dilation with all calyces uniformly dilated and normal renal parenchyma), and Grade-4 (similar to Grade-3 but with thinning of the renal parenchyma). The bladder was checked for abnormalities in the bladder wall (normal bladder wall thickness is $2-4.5 \mathrm{~mm}$ when empty and $1-3 \mathrm{~mm}$ when full). The ureters were checked for presence of dilatation (normal ureters are generally not visualized by ultrasound).

All the data collected through the proforma were entered into the Statistical Package for Social Sciences version 18 (SPSS Inc., Chicago, IL, USA) and analyzed through its statistical calculations. Means and standard deviations were calculated for age, while frequencies and percentages were calculated for gender and different CAKUT.

\section{RESULTS}

A total of 150 cases were included in this study during the study period. Regarding age distribution, 63 neonates $(42.0 \%)$ were 1-10 days old, 52 neonates $(34.7 \%)$ were between 11-20 days of age, while 35 neonates $(23.3 \%)$ were $21-28$ days old. Mean age of the neonates was $13.8 \pm 7.5$ days. Seventy-six $(50.7 \%)$ neonates were male and 74 (49.3\%) were female.

Distribution of the cases by CAKUT showed that $10(6.7 \%)$ neonates out of the sample had these anomalies. Most neonates had more than one anomaly. The left side was involved in 6 neonates while the right side was involved in four.

Hydronephrosis was the most common abnormality found in $8(5.3 \%)$ cases (table). Two $(1.3 \%)$ neonates had Grade-2 hydronephrosis. One $(0.7 \%)$ case

Table: Frequency of different congenital anomalies of the kidney and urinary tract by means of ultrasound in neonates.

\begin{tabular}{l|c|c}
\hline Anomalies & Frequency & Percentage \\
\hline Unilateral Absence & - & - \\
\hline $\begin{array}{l}\text { Abnormal Location (Ectopic } \\
\text { Kidneys) }\end{array}$ & 2 & 1.3 \\
\hline Dimensional Abnormality & 7 & 4.7 \\
\hline Asymmetry of Left And right & 5 & 3.3 \\
\hline Abnormal Corticomedullary & 5 & 3.3 \\
Differentiation & 8 & 5.3 \\
\hline Hydronephrosis & - & - \\
Grade-1 & 2 & 1.3 \\
Grade-2 & 1 & 0.7 \\
Grade-3 & 5 & 3.3 \\
Grade-4 & 3 & 2.0 \\
\hline Hydroureter & 2 & 1.3 \\
\hline Urinary Bladder Abnormalities &
\end{tabular}


had Grade-3 and 5 (3.3\%) neonates had Grade-4 hydronephrosis. The location of kidneys was abnormal (ectopic) in $2(1.3 \%)$ neonates. Abnormal dimension was seen in $7(4.7 \%)$ cases and abnormal corticomedullary differentiation was found in $5(3.3 \%)$ cases. Non-symmetrical cases were 5 (3.3\%). Hydroureter was observed in $3(2 \%)$ neonates and urinary bladder was abnormal in $2(1.3 \%)$ neonates.

\section{DISCUSSION}

Ultrasonography is the first imaging method of choice to evaluate urinary assessment of infants both antenatally and postnatally ${ }^{10}$. Ultrasonography has many advantages such as non-invasiveness, costefficiency, and easy accessibility. Using ultrasonography, the prevalence of urinary anomalies has been observed between $0.1-2.3 \%{ }^{11}$.

In the present study, the frequency of CAKUT was $6.7 \%$ and it was a bit higher than that demonstrated in previous studies e.g. Li et al, $(0.16 \%)^{2}$, Isac et al, $(0.6 \%)^{3}$, Riccipetitoni et al, $(1.04 \%)^{12}$, Sakuma and Ogawa $(3.7 \%)^{13}$, Tsuchiya et al, $(3.5 \%)^{14}$, and Himmetoglu et al, $(0.27 \%)^{15}$. The greater determine in our study was thought to be due to the study design. The research was performed in a tertiary-care hospital to which selected sick newborns were referred with complex childbirth defects, and it also included samples from the department of pediatric nephrology.

In our study, the abnormalities on the left side were dominating the abnormalities on the right side. In a large sample study of 11,887 newborn infants, extended over a period of ten years, the left side dominated in $78(68.4 \%)(p<0.05)^{16}$. The study also observed an association of gender with the frequency of CAKUT. One-hundred \& forty-two $(79.3 \%)$ males had CAKUT while significantly less $(p<0.001) 37(20.7 \%)$ females had the anomalies ${ }^{16}$. In a systematic review, the abnormalities were more often identified in males and were more often located on the left side ${ }^{17}$. A meta-analysis specifically performed on the distribution of different unilateral anomalies found that the left side was affected in $53 \%, 57 \%, 56.9 \%, 63.2 \%$ and $62.5 \%$ of the patients ${ }^{18}$. Another study observed renal malformations more on the left side and ureteral malformations more on the right side with boys affected more than girls in a ratio of 1.4:13. The accurate processes prompting these lateralizations stay to be resolved yet may include vascular development, differential gene expression, or susceptibility to ecological factors, e,g. hypoxia.

Hydronephrosis, with a rate of $5.3 \%$, was the most common anomaly found in our study. Similarly, hydronephrosis was the most frequent anomaly seen by Tabel and colleagues ${ }^{19}$, in a Turkish study. Other anomalies were ureteropelvic stenosis $(3.4 \%)$, vesicoureteral reflux $(2.3 \%)$, multicystic dysplastic kidney $(0.3 \%)$, posterior urethral valve $(1.6 \%)$, renal agenesis $(0.4 \%)$, and ectopic kidney $(0.1 \%)$. Postoev and coworkers, also observed congenital hydronephrosis as the most prevalent malformation ( $14.2 \%$ of all cases) in a Russian study including 50,936 singletons from the Murmansk County Birth Registry ${ }^{20}$. A German study found hydronephrosis in $179(1.5 \%)$ newborn infants trailed by nephrocalcinosis $(\mathrm{n}=32)$, double-kidneys $(\mathrm{n}=28)$, and horseshoe kidneys $(\mathrm{n}=13)^{17}$. In an Indian study, supervised by Kumar et al21, hydronephrosis was the most common anomaly, seen in 61 cases, out of a sample of 587 cases. This was followed by bilateral cystic kidney in 50/587 cases. In a Chinese study, urinary ultrasound screening was performed in 8827 infants ${ }^{22}$. Eleven cases of hydronephrosis, seven cases of unilateral renal aplasia, two cases of renal duplication, two cases of renal dysplasia, one case of multicystic dysplastic kidney, one case of renal ectopia, one case of ureterectasia, and one case of renal cyst were observed. A Romanian study, observed hydronephrosis in 187 children followed by dysplastic kidney $(n=22)$, urethral duplicity $(n=21)$, and renal agenesis $(n=20)^{3}$. A Korean study further endorsed this assumption, that hydronephrosis is the most noted CAKUT in newborns followed by duplicate kidneys ${ }^{8}$.

Concluding, ultrasound has been effective for early detection of CAKUT. It is imperative to identify and distinguish between the abnormalities that may remain obscure in the newborn and those that are incompatible with life. In case of the earlier problems, the renal functions can be saved if they are diagnosed during pregnancy while the latter may necessitate a therapeutic abortion. The children with CAKUT that are born without an obvious malformation at birth, mostly remain asymptomatic for a long time, sometimes even till adulthood. At times, CAKUT appear as part of a systemic disease affecting other parts of the body as well. At general, CAKUT present with proteinuria and/or hypertension in adulthood ${ }^{23}$, and pose significant renal problems to the effect that many of these patients ultimately require urinary dialysis or transplantation ${ }^{10}$.Provision of ultrasonographic screening of neonatal CAKUT to the infants that are born in the tertiary-care hospitals and those that are admitted to such centers for any cause, is a valuable service. This policy may help to establish prompt diagnosis of any 
urinary abnormality that may get further complicated without timely treatment and/or intervention.

\section{CONCLUSION}

The frequency of CAKUT in neonates by means of postnatal ultrasound examination in our sample was $6.7 \%$. Hydronephrosis was the most common anomaly found in our sample. Ultrasound is effective for early detection of CAKUT and is recommended in the immediate postnatal period to establish prompt diagnosis of urinary tract abnormalities.

\section{CONFLICT OF INTEREST}

This study has no conflict of interest to be declared by any author.

\section{REFERENCES}

1. Capone VP, Morello W, Taroni F, Montini G. Genetics of congenital anomalies of the kidney and urinary tract: the current state of play. Int J Mol Sci 2017; 18(4): 796-99.

2. Li ZY, Chen YM, Qiu LQ, Chen DQ, Hu CG, Xu JY, et al. Prevalence, types, and malformations in congenital anomalies of the kidney and urinary tract in newborns: a retrospective hospitalbased study. Ital J Pediatr 2019; 45(1): 50-54.

3. Isac R, Stroescu R, Olariu C, Pop M, Farkas F, Ardelean M, et al. Diagnosis and clinical consequences of urinary tract malformation in children. Revista Societății Române de Chirurgie Pediatr 2019; 22(1): 27-30.

4. Rydberg C, Tunón K. Detection of fetal abnormalities by secondtrimester ultrasound screening in a non-selected population. Acta Obstet Gynecol Scand 2017; 96(2): 176-82.

5. Dulgheroff FF, Peixoto AB, Petrini CG, Caldas TMRDC, Ramos DR, Magalhães FO, et al. Fetal structural anomalies diagnosed during the first, second and third trimesters of pregnancy using ultrasonography: a retrospective cohort study. Sao Paulo Med J 2019; 137(5): 391-400.

6. Liu $\mathrm{S}, \mathrm{Wu} \mathrm{Q}$, Chen $\mathrm{Z}$. Fetal anomalies detection in China by screening with ultrasound. Biomed Res 2017; 28(11): 4891-96.

7. Riaz M, Manzoor U, Anwar H, Khalid A. Diagnostic Accuracy of Early Ultrasound for Congenital Anomalies. Ann Punjab Med Coll 2017; 11(4): 295-99.

8. Choi HA, Lee DJ, Shin SM, Lee YK, Ko SY, Park SW. The prenatal and postnatal incidence of congenital anomalies of the kidneys and urinary tract (CAKUT) detected by ultrasound. Child Kidney Dis 2016; 20(1): 29-32.
9. Stolz G, Schumacher R, Wiesel A, Schlaefer K, Queisser-Luft A. Prä-und postnatales nierenscreening im vergleich: eine Analyse von 34.450 Neugeborenen des geburtenregisters mainzer modell [Pre- and postnatal kidney screening compared: an analysis of 34,450 newborn infants of the Mainz model birth register]. Radiol 2002; 42(8): 630-36.

10. Srivastava R. Challenge of congenital abnormalities of the kidney and urinary tract. Asian J Pediatr Nephrol 2018; 1(2): 49-51.

11. Nef S, Neuhaus TJ, Spartà G, Weitz M, Buder K, Wisser J, et al. Outcome after prenatal diagnosis of congenital anomalies of the kidney and urinary tract. Eur J Pediatr 2016; 175(5): 667-76.

12. Riccipetitoni G, Chierici R, Tamisari L, De Castro R, Manfredi S, Veroni G, et al. Post-natal ultrasound screening of urinary malformations. J Urol 1992; 148(2Pt-2): 604-605.

13. Sakuma T, Ogawa O. [Ultrasonographic screening in healthy 3month-old children for congenital malformations of the urinary tract]. Nippon Hinyokika Gakkai Zasshi 1998; 89(2): 468-76.

14. Tsuchiya M, Hayashida M, Yanagihara T, Yoshida J, Takeda S, Tatsuma N, et al. Ultrasound screening for renal and urinary tract anomalies in healthy infants. Pediatr Int 2003; 45(5): 617-23.

15. Himmetoglu O, Tiras MB, Gursoy R, Karabacak O, Sahin I, Onan A. The incidence of congenital malformations in a Turkish population. Int J Gynaecol Obstet 1996; 55(2): 117-21.

16. Gruessner SE, Klein K, Peter C, Bueltmann E, Wagner J, Klingmueller V. Ultrasound screening of the kidneys and urinary tract in 11.887 newborn infants: a 10-year experience. Open J Obstet Gynecol 2012; 2(4): 389-93.

17. Westland R, Schreuder MF, Ket JC, van Wijk JA. Unilateral renal agenesis: a systematic review on associated anomalies and renal injury. Nephrol Dial Transplant 2013; 28(7): 1844-55.

18. Schreuder MF. Unilateral anomalies of kidney development: why is left not right. Kidney Int 2011; 80(7): 740-45.

19. Tabel Y, Haskologlu ZS, Karakas HM, Yakinci C. Ultrasonographic screening of newborns for congenital anomalies of the kidney and the urinary tracts. Urol J 2010; 7(3): 161-67.

20. Postoev VA, Gribovski AM, Kovalenko AA, Anda EE, Nieboer E. Congenital anomalies of the kidney and the urinary tract: A murmansk county birth registry study. Birth Defects Res A Clin Mol Terato 2016; 106(3): 185-93.

21. Kumar M, Thakur S, Puri A, Shukla S. Fetal renal anomaly: factors that predict survival. J Pediatr Urol 2014; 10(6): 1001-1007.

22. Gong Y, Zhang Y, Shen Q, Xiao L, Zhai Y, Bi Y, et al. Early detection of congenital anomalies of the kidney and urinary tract: cross-sectional results of a community-based screening and referral study in China. BMJ Open 2018; 8(5): e020634.

23. Jain S, Chen F. Developmental pathology of congenital kidney and urinary tract anomalies. Clin Kidney J 2018; 12(3): 382-99. 